\title{
Dynamika zmian w obrębie rytuału i doktryny w wybranych religiach Bengalu ${ }^{1}$
}

\author{
Robert Czyżykowski \\ Instytut Religioznawstwa \\ Uniwersytet Jagielloński
}

\begin{abstract}
Dynamic of Changes in the Ritual and Doctrine of Selected Religions of Bengal
\end{abstract}

The historical Bengal is spread throughout the north-eastern part of the Indian subcontinent. From the perspective of religious studies, this region is a very interesting field of research. In the Bengal area we find the activity of the main religious traditions of South-East Asia, namely Hinduism, Buddhism and Islam. Their mutual interactions brought into existence many original and syncretic religious phenomena. They are characterised by archaic schemes of thinking and practices which are relatively stable; however, the symbolism and meanings correlated with them are invariant. Tantric practices - visualisations, mantras and Yogic control of the body - are elements of this very persistent system.

Key words: religions of Bengal, ritual, Tantra

Słowa kluczowe: religie Bengalu, rytuał, tantra

\section{Wielki Bengal i badania religioznawcze}

Historyczny Bengal sytuujący się na północnym wschodzie subkontynentu indyjskiego, a którego obszar zajmują obecnie indyjski stan Bengal Zachodni oraz Bangladesz, stanowi z religioznawczego punku widzenia niezwykle interesujący przedmiot badań. Wynika to przede wszystkim z bogatej i złożonej historii tego regionu,

${ }^{1}$ Artykuł powstał jako rezultat badań nad problematyką tantrycznych wisznuickich religii Bengalu w ramach projektu badawczego: Trwatość i transformacja wiedzy religijnej $w$ wisznuickich religiach Bengalu. Projekt został sfinansowany ze środków Narodowego Centrum Nauki przyznanych na podstawie decyzji numer DEC-2013/11/D/HS1/04359 (realizacja: lata 2014-2017). 
obejmującej ponad dwa tysiące lat, względnej izolacji od cywilizacji Indoariów oraz usytuowaniu na przecięciu ważnych szlaków komunikacyjnych we wschodniej części subkontynentu indyjskiego ${ }^{2}$. Aktywność na terenie Bengalu znaczących nurtów religijnych Azji Południowo-Wschodniej, mianowicie hinduizmu, buddyzmu oraz islamu, ich wzajemne przenikanie się, współegzystowanie oraz wypieranie - wszystko to doprowadziło do wykształcenia się wielu oryginalnych i synkretycznych form religii. Wyjątkowe usytuowanie geograficzne Bengalu na rubieżach kultury Indoariów, z otwarciem jednak na Zatokę Bengalską i handel morski z innymi obszarami Azji Południowo-Wschodniej, zadecydowało o szczególnej roli Bengalu jako mediatora ekonomicznego i kulturowego pomiędzy cywilizacjami indyjskimi, kulturami Azji Wschodniej (także obszaru Indochin) oraz kulturami regionu Himalajów. Mamy tu do czynienia z nałożeniem się wpływów najbardziej znaczących religii subkontynentu indyjskiego, w tym dwóch religii uniwersalnych: buddyzmu oraz islamu ${ }^{3}$. Formy inicjacyjne, które wykształciły się na terenie Bengalu, niewątpliwie decydują o wyjątkowości tego obszaru, ponieważ z jednej strony stanowią dziedzictwo religii niearyjskich, z drugiej zaś strony są naznaczone silnym synkretyzmem. Stąd badania religioznawcze tego obszaru charakteryzują się ogromnym potencjałem, czego dowodem jest duża liczba publikacji poświęconych religiom Bengalu ${ }^{4}$. Mimo iż niniejszy artykuł wykorzystuje dane z religii bengalskich, to założenia i wnioski z niego wynikające mogą mieć charakter uniwersalny i pomóc w sformułowaniu ogólnych prawidłowości oraz schematów dotyczących rozwoju i transformacji zjawiska religii, a także wzmacniać lub osłabiać istniejące już teorie.

Zgodnie z tą deklaracją należałoby wstępnie przedstawić elementy charakteryzujące obszar Bengalu i determinujące jego specyfikę:

- silne oddziaływanie religii niearyjskich, wynikające między innymi z oddalenia od głównego obszaru będącego pod oddziaływaniem cywilizacji plemion indoaryjskich;

2 A. Chattopadhyaya, The People and Culture of Bengal, a Study in Origins, vol. I, Kolkata 2002.

${ }^{3}$ Hinduizm od wieków średnich również może być uznany za religię o charakterze uniwersalistycznym. Niezwykłe nasilenie tego procesu nastąpiło na przełomie XIX i XX w. w nurcie tak zwanego renesansu bengalskiego. Jednak przykłady konwersji na różnorakie nurty hinduizmu znane są już od starożytności, na przykład poseł grecki króla Balabhadry (Balabhadra) z hellenistycznego królestwa Taxili, Heliodor (Heliodorus) wspominany na kolumnie w Widiszy (okolice Bhopalu). Był on prawdopodobnie pierwszym zachodnim konwertytą na wisznuizm (,Journal of the Royal Asiatic Society”, London: JRAS, Pub., 1909, s. 1053-1054). Jednak jasne samookreślenie się religii hinduistycznych jako mających wspólne jądro z innymi religiami i jako dostępnych dla wszystkich - bez ograniczeń kastowych - następuje w średniowieczu. Przykładem może być właśnie wisznuizm bengalski, który w XVI w. przyjmował konwertytów z różnych nurtów hinduizmu, buddyzmu, a nawet $\mathrm{z}$ islamu (za co groziła kara śmierci). Zob. T.K. Stewart, Godna naśladowania pobożność stugi Hariego [w:] Praktyki religijne w Indiach, D. Lopez (red.), Warszawa 2001. W tekstach tejże tradycji funkcjonuje koncepcja najwyższego bóstwa Kryszny, natomiast imiona i desygnaty innych najwyższych bóstw, na przykład Allaha, mają się odnosić do tej samej najwyższej istoty (idea taka wyrażona jest w hagiografii Ćajtanji, Ćajtanja-bhagawata, ibidem). Inicjacja w wisznuizmie bengalskim (Ćajtanji, Caitanya) była dostępna dla wszystkich, bez względu na ich status, niemniej jednak dominującą rolę zajmowali w nim bramini.

${ }^{4}$ Kalkuckie ośrodki naukowe są jednymi z najstarszych nowożytnych instytucji tego rodzaju na subkontynencie indyjskim. Do dziś religie Bengalu stanowią jeden z popularnych obszarów badawczych indologów i religioznawców zachodnich. 
- wynikający z powyższego brak wykształconej klasycznej indoaryjskiej struktury społecznej: cztery warny (varna $)^{5}$;

- silna rola kultów skoncentrowanych na różnych formach kultu bogini, a zatem:

- dominacja śaktyzmu - spośród głównych gałęzi hinduizmu najliczniejszą religią Bengalu jest śaktyzm;

- istotna rola religii plemiennych i tantry, element ten pojawia się nie tylko w śaktyzmie, ale również w wisznuizmie, czego przykładem jest dominujący kult bogini Radhy $(R \bar{a} d h \bar{a})$, towarzyszki Kryszny $(K r s \underline{n} n a)^{6}$;

- do XIII wieku Bengal i generalnie północno-wschodnie Indie to obszar silnej aktywności buddyzmu tantrycznego; miejsce to charakteryzuje bliskość starożytnych i średniowiecznych ośrodków buddyjskich w Biharze (na przykład Nalanda, Paharpur);

- region ten był blisko powiązany z aktywnością ,wielkich doskonałych” (mahasiddhów, māhasiddha) uznawanych w wadźrajanie (vajrayana), nurtach tantrycznych i jodze $\mathrm{7}^{7}$. Notujemy obecność legend o nath-joginach - Matsjendrze (matsyendra), Gorakszy (gorakșa) oraz Gopićandrze (gopicandra), co można wiązać z popularnością praktyk jogicznych o charakterze tantrycznym. Ponadto Wielki Bengal ${ }^{8}$ jest jedynym z nielicznych obszarów, gdzie zachowały się relikty wadźrajany9: od XVI do XVII wieku odnotowuje się tam obecność buddyzmu tantrycznego, natomiast we wschodnim Bengalu, w Ćittagongu, aż do XIX wieku ${ }^{10}$.

Elementem dopełniającym ten złożony pejzaż religijny jest obecność od XI wieku islamu, zaś począwszy od XIII-XV wieku jego dominacja na znaczących obszarach Bengalu, zwłaszcza wschodniego (współczesny Bangladesz). Wynikiem tego jest także silna pozycja zakonów sufickich w Bengalu oraz tradycja literacka związana $\mathrm{z}$,jogą suficką" (zob. niżej) ${ }^{11}$.

${ }^{5}$ Należy jednak zaznaczyć, że system dźati (jatī, tzw. kast) istnieje w formie analogicznej do innych regionów Indii. Zob. A. Chatopadyaya, op.cit.

${ }^{6}$ Zob. na przykład B. Grabowska, Powstanie, rozkwit i zmierzch liryki wisznuickiej XII-XX w., Warszawa 1995, R. Czyżykowski, Droga do doskonałości w tradycji Ćaitanji. Wybrane aspekty praktyki religijnej w wisznuizmie bengalskim, Kraków 2003.

${ }^{7}$ Zob. na przykład R.M. Davidson, Indian Esoteric Buddhism. Social History of the Tantric Movement, Delhi 2002.

${ }^{8}$ Bengal wraz z przyległymi prowincjami objętymi jego oddziaływaniem: Orisa, Asam i zachodnia część Biharu.

9 Teksty wisznuickie z XVI-XVII w. dostarczają informacji o interakcjach pomiędzy wisznuitami a buddystami, można dostrzec zarówno antagonizmy, jak i proces asymilacji elementów buddyzmu przez rozwijający się wisznuizm (wchłonięcie pozostałości gmin buddyjskich dokonało się nie tylko przez hinduizm, ale w dużym stopniu przez islam). Zob. Kṛṣnadāsa Kavirāja, Caitanya Caritāmṛta, thum. i wprow. E.C. Dimock Jr., wprow. i wyd. T.K. Stewart, Cambridge-London 1999, Premadāsa, Ānandabhairava [w:] Caitanya prathama cārițī sahajiyā punthi, Paritoṣ Dāsa (red.), wprow. Gopīnātha Kavirāja, Calcutta 1972.

${ }^{10}$ Wbrew popularnym opiniom, że buddyzm całkowicie zniknął z Indii w XIII w.

${ }^{11}$ M.E. Haq, A History of Sufism in Bengal, Dacca 1975, K.E. Cantu, Theurgy and the Snake: The Yoga Kalandar and Bengali Sufism, Saarbrücken 2015, oraz S. Hatley, Mapping the Esoteric Body in the Islamic Yoga of Bengal, „History of Religions” 2007, vol. 46, nr 4, s. 351-368. 


\section{Podstawowa klasyfikacja. Nurt sahadźija}

Dominującymi nurtami religijnymi Bengalu były: buddyzm, hinduizm oraz islam, a także ich odłamy. Podpowierzchniowo sytuuje się nurt tantryczny zasilający zarówno wymienione główne nurty religijne, jak i religie ludowe (będący w jakimś stopniu także substratem dla powstania grup tantrycznych ${ }^{12}$ ). Jest on trudno definiowalny, będąc bezpośrednio związany z głównymi grupami religijnymi lub stanowiąc ich część. Nurt tantryczny może też funkcjonować samodzielnie w postaci grup synkretycznych. Właśnie takim niejasnym i trudnym do definiowania substratem dla wielu religii Bengalu jest tak zwany nurt sahadźija (sahajiyā $)^{13}$. Stanowi on próbę transcendencji ograniczeń tradycyjnych religii i ich podziałów, hierarchii społecznej i klasycznych pojęć wypracowanych na polu indyjskich teologii oraz filozofii (negacja spekulacji (anumäna) i oparcie się na bezpośrednim doświadczeniu generowanym przez rytuał). Nurt sahadźija wychodzi poza komponenty i osnowę kulturowo osadzonych systemów religijnych: dharmy rozumianej jako prawo kosmiczne i zestaw obowiązków określonych klas społecznych hierarchicznie zorganizowanego społeczeństwa (varṇa, jatî), środowiska społecznego (kula - klan) oraz języka (bhāsa). To nurt przede wszystkim o charakterze mistycznym (w sensie stosowania praktyk w celu osiągnięcia takiego doświadczenia), odwołujący się do obecnego w człowieku pierwiastka niematerialnego inherentnie stopionego $\mathrm{z}$ ciałem. Nie jest to koncepcja dualistyczna pojmująca niematerialną, „duchową" zasadę jako zamkniętą w ciele: samo ciało jest potencjalnie medium prowadzącym do wyzwolenia. Takie podejście wraz z uniwersalnym kompleksem rytualnym, oprócz obecności tych koncepcji w hinduizmie i buddyzmie tantrycznym, otworzyło także pole do powstania synkretycznych postaci religii, takich jak na przykład baulowie (baul) czy kartabhadźowie $(\text { kartābhajāa })^{14}$. Nurt sahadźija funkcjonuje w ten sposób jako substrat dla tantrycznych form religii bengalskich, zarówno buddyzmu, jak i hinduizmu oraz sufizmu. Z kolei wspomniana obecność nath-joginów oraz buddyzm wadźrajany przyczyniły się do szerszego wykorzystania lub wzmocnienia hatha-jogi i jogi tantrycznej w wielu nurtach religijnych Bengalu.

12 S.B. Dasgupta, Obscure Religious Cults as Background of Bengali Literature, Calcutta 1995, G. Samuel, The Origins of Yoga and Tantra; Indic Religions to the Thirteenth Century, Cambridge 2008.

${ }^{13}$ Literatura poświęcona zjawisku nurtu sahadźija w Bengalu: S.B. Dasgupta, op.cit., M.M. Bose, The Post-Caitanya Sahajiyā Cult of Bengal, Calcutta 1930, P. Das, Sahajīya Cult of Bengal and Pancha Sakha Cult of Orissa, Calcutta 1988, E.C. Dimock, The Place of the Hidden Moon: Erotic Mysticism in the Vaiṣnava Sahajīya Cult of Bengal, London-Chicago 1989, P. Das, Sahajiyā o gaudīya vaiṣnava dharma, Calcutta 1978, G.A. Hayes, Metaphoric Worlds and Body Symbolism in Vaiṣnava Sahajiyā Tantric Traditions" [w:] Yoga: Essays on the Indian Tradition, I. Whicher (red.), London 2003; idem, Tradycje wisznuizmu sahadźija w średniowiecznym Bengalu [w:] Praktyki religijne w Indiach, S. Lopez (red.), Warszawa 2002, idem, The Necklace of Immortality: A Seventeenth-Century Vaiṣnava Sahajiyā Text [w:] Tantra in Practice, D.G. White (red.), Delhi 2001, J. McDaniel, The Madness of the Saints:Ecstatic Religion in Bengal, Chicago 1989, R.P. Das, Problematic Aspects of the Sexual Rituals of the Bauls of Bengal, „Journal of the American Oriental Society” 1992, vol. 112, nr 3, s. 388-432.

${ }^{14}$ H.G. Urban, Ecstatic Songs of Bengal, Tantric and Devotional Songs from Colonial Bengal, Oxford 2001. 


\section{Zagadnienia metodologiczne}

Nieprzypadkowo artykuł stara się objąć jako przedmiot swojej analizy wydzielony obszar Bengalu. W opinii autora, jego wyodrębnienie jest warunkiem sprzyjającym analizie opartej na metodzie przekrojowej, fenomenologicznej, starającej się zanalizować zjawiska religijne trwające w sposób względnie stały, niezależne od zmiennego środowiska historycznego i dominującej religii w danym okresie. Rozpatrywane tu schematy i prawidłowości w rozwoju oraz ewolucji fenomenu religii mogą być obserwowane i adekwatnie przetestowane jedynie na mniejszych obszarach i w węższych przedziałach czasowych. Analiza danych dotyczących zjawisk religijnych obejmujących zbyt duży obszar może skutkować nieuprawnioną komparatystyką (na przykład dane z dwóch odległych geograficznie i cywilizacyjnie kręgów), kiedy to pewne fenomeny są pozornie analogiczne wobec siebie. Może to prowadzić do powierzchownych wniosków, za co wielokrotnie krytykowano fenomenologię religii, która analizowała zjawiska religijne, globalnie wyrywając je z oryginalnego kontekstu i podporządkowując szerszej teorii.

Dlatego zawężony do Bengalu obszar badawczy jest zwarty i bierze pod uwagę rozbudowany kontekst: historyczny, kulturowy, geograficzny, w którym funkcjonują interesujące nas zjawiska religijne. Wreszcie, takie ujęcie dostarcza uprzywilejowanej pozycji badawczej ze względu na fakt zgrupowania na stosunkowo małym obszarze różnorodnych grup religijnych pozostających jednocześnie $\mathrm{z}$ sobą $\mathrm{w}$ długotrwałych interakcjach. Przedmiotem niniejszego artykułu będzie próba ukazania ogólnych prawidłowości w rozwoju religii bengalskich odnoszących się do elementów rytualnych, a w dalszej kolejności - doktryny. Podstawą tych rozważań jest hipoteza o wysokiej trwałości struktur rytualnych względem doktryn towarzyszących rytuałowi. W grę wchodzą tu aspekty: znaczeniowy i symboliczny, które mogą względnie łatwo ulegać zastąpieniu przez inny system symboliczny. Takie ujęcie jest oparte między innymi na teorii Fritsa Staala, który sformułował ją na podstawie swoich długoletnich badań nad rytuałem wedyjskim ${ }^{15}$ oraz innymi tradycjami religijnymi Azji ${ }^{16}$. Nie będę tu rozwijał szczegółowo strony teoretycznej koncepcji Staala, wystarczy nakreślenie jego podstawowych założeń.

Kluczowe w nakreślanej koncepcji jest przekonanie o tym, że dany element rytuału denotuje określone znaczenie nie autonomicznie, a jedynie w określonym kontekście. Ewentualne znaczenia elementów rytuału są przyporządkowywane arbitralnie i zdeterminowane przez daną tradycję religijną i kulturę. A te, w przeciwieństwie do samego rytuału, są zmienne. Używając terminologii lingwistycznej, możemy stwierdzić,

${ }^{15}$ F. Staal, The Meaningless of the Ritual, „Numen” 1979, vol. XXVI, fasc. I, ibidem, The Sound of Ritual, vol. XXIII, fasc. I. Najobszerniejsze przedstawienie jego stanowiska można znaleźć w zbiorze The Rules without Meaning. Ritual, Mantras and the Human Sciences, New York-Bern-Frankfurt am Main-Paris 1989, wyd. indyjskie: Ritual and Mantras. Rules without Meaning, New Delhi 1996.

16 W komparatystyce archaicznej „gramatyki rytualnej” od początku badań ważną rolę oprócz danych z kultury wedyjskiej odgrywały dane z zakresu rytuału izraelskiego (Mauss). Zob. N.S. Meshel, The 'Grammar' of Sacrifice: A Generativist Study of the Israelite Sacrificial System in the Priestly Writings with a 'Grammar' of $\Sigma$, Oxford 2014. Termin ,gramatyka” użyty jest w szerokim, nielingwistycznym sensie. 
że syntaktyka rytuału jest stała, zaś jego semantyka zmienna. Rytuał jest bardziej pierwotny niż mit czy doktryna religijna, a sama rytualizacja to zjawisko wspólne dla wielu gatunków. Zdaniem Staala, rytuał jest „pustą” strukturą, która może być intepretowana i „oblepiana” lub wypełniana znaczeniami w sposób elastyczny i dynamiczny. Rytuał nie posiada znaczenia, gdy jest rozpatrywany w kategoriach swojej struktury, jawi się on wtedy jako układ autoteliczny, działający per $s e^{17}$. Semantyka poszczególnych elementów rytuału jest wtórna, elementy te nie znaczą nic w oderwaniu od kontekstu kulturowego. Oczywiście, nawet „czysta” struktura rytualna może mieć dowolne znaczenie, nie funkcjonuje ona przecież w pustce kulturowej.

Jak wskazuje Meshel, bezznaczeniowość rytuału u Staala może być rozumiana dwojako: 1) jako asemantyczność rytuału (,rytuał jest czystą składnią, bez semantyki”) lub 2) irracjonalność rytuału, to znaczy brak jego celowości lub też irracjonalność w sensie Ottowskim ${ }^{18}$. Stąd pojęcie ,znaczenia” jest u Staala niejasne. Mimo że pojęcie znaczenia i referencyjności w tej teorii jest kwestią sporną, nie umniejsza to znaczenia ani całości teorii Staala, ani samej koncepcji dominanty struktur rytualnych nad obszarem znaczeniowym i symbolicznym rytuału, do której odnoszę się w tym artykule. Na użytek niniejszego artykułu przyjmę zatem, że chodzi o referencyjność elementów rytuału, która może być zmienna i kształtować się w zależności od zmiany kontekstu kulturowego, historycznego itd. Zatem rytuał (jego struktura) jest względnie stały, z kolei symbolika mu przypisywana - zmienna i niestała. Ten właśnie fakt daje rytuałowi, w połączeniu ze skutecznością w zakresie wywoływania określonych stanów psychicznych (ASC) i silnych emocji, niezwykłą moc oddziaływania (doświadczenie religijne). Może ono wyrażać się w postaci wzmocnionej wiary w tenże rytuał oraz w presji na jego przekazywanie w obrębie danej tradycji.

Przywołana skuteczność rytualna zyskuje szczególne znaczenie w przypadku rytuału zinternalizowanego, będącego przede wszystkim pracą $\mathrm{z}$ organizmem psychofizycznym, jak w przypadku praktyk jogi tantrycznej, stanowiącej rdzeń nurtu sahadźija. W odniesieniu do niniejszego materiału koncepcja Staala ma ograniczone zastosowanie, służy bardziej jako inspiracja niż ściśle zastosowana metoda badawcza. Kluczowa pozostaje jednak teza o prymarności rytuału nad doktryną, elastyczności semantyki i trwałości syntaktyki oraz konkretnych metod generowania „zmienionych stanów świadomości". (Staal uznaje praktyki medytacyjne czy mistycyzm za czwarty filar religii, obok klasycznych trzech: doktryny, kultu, organizacji). Innymi słowy, możemy mówić o dominancie rytualnej (praktycznej) strony religii nad doktrynalną, wyrażającej się w przewadze ortopraksji nad ortodoksją, jak podkreśla Staal, swoistej dla religii azjatyckich. Elastyczność procesu przyporządkowania znaczenia i symboliki stałym strukturom rytualnym ma oczywiście szersze implikacje. Ten sam rytuał czy też różne formy dyscypliny cielesnej ze względu na ich skuteczność i możliwość generowania intensywnych doświadczeń o charakterze wizyjnym

${ }^{17}$ Niniejszy artykuł nie jest próbą zajęcia zdecydowanego stanowiska w kwestii kontrowersyjnej koncepcji „bezznaczeniowości rytuału” (meaningless of ritual). Zob. na przykład polemiczny artykuł: H. Penner, Language, Ritual and Meaning, „Numen. International Journal of the History of Religions” 1985, vol. 32. Wydaje się zresztą, że nadmierna krytyka, z jaką spotkała się ta koncepcja, jest w dużej mierze nieuzasadniona, wynika bowiem $\mathrm{z}$ braku jej zrozumienia.

${ }^{18}$ N.S. Meshel, op.cit., s. 188. 
czy ekstatycznym odznaczają się niezwykłą trwałością (jeśli chodzi o ich przekaz w danej społeczności i jego praktyczną aplikację). Może on być stosowany zamiennie w obrębie jednej tradycji lub wielu różnych grup, aby osiągnąć różne cele religijne. Struktura rytualna pozostaje względnie stała, zmienia się referencyjność rytuału lub też jego charakter, na przykład następuje tak zwana internalizacja (interioryzacja) rytualna.

$\mathrm{W}$ rozpatrywanym przypadku $\mathrm{w}$ procesie generowania zjawiska religii (rozumianej przede wszystkim jako kompleks inicjacyjny i doświadczenie religijne) dwa aspekty odgrywają kluczową rolę, a mianowicie: archaiczne formy myślenia i konceptualizacji rzeczywistości oraz rytualizacja będąca prawdopodobnie pierwotnym dziedzictwem gatunku homo sapiens. Można zaryzykować stwierdzenie, że te elementy tłumaczą niezwykłą trwałość rozpatrywanych tu form religii. Te pierwotne formy myślenia wyrażają się przede wszystkim w systemie ekwiwalencji mikro-makrokosmicznych, przekonaniu o bytowaniu w ciele nieśmiertelnego pierwiastka (schemat płynno-ognistej rzeczywistości, boski napój nieśmiertelności (amrta), ,kropla" świadomości, życia (bindu) ${ }^{19}$, elementy tradycyjnych nauk medycznych, płynne „humory” (sanskr. doṣa, dosł. „błąd"20) pełniące funkcję regulacyjną dla organizmu, dyscyplinie polegającej na retencji płynów prokreacyjnych), ujęciu rzeczywistości jako opozycyjnych pierwiastków męsko-żeńskich (symbolizowanych przez binarność solarno-lunarną) oraz koncepcji, że owe dwa pierwiastki pierwotnie stanowiły jedność (preakreacyjna sahaja). Celem wszelkich praktyk powinno być urzeczywistnienie we własnym ciele fuzji tych dwóch opozycyjnych zasad kosmicznych, co jest równoznaczne ze stanem wyzwolenia. Tak nakreślone struktury myślenia są także charakterystyczne dla praktyk nurtów tantrycznych ${ }^{21}$ i tworzą to, co możemy nazwać doktryną tantryczną. W toku praktyki rytuał potwierdza doktrynę przyjętą od nauczyciela i kompleks mityczny swoisty dla danej rzeczywistości kulturowej. Zatem nie tylko struktury rytualne są trwałe, ale także metody przekazu takiej wiedzy wraz z jej praktyczną aplikacją. Wysoką trwałość rozpatrywanych tutaj ezoterycznych praktyk o charakterze jogicznym i tantrycznym oraz procesu ich transmisji, które odnotowujemy w Bengalu, można tłumaczyć właśnie czynnikami o takim charakterze. W ten sposób zapewniają one skuteczność generowania „zmienionych stanów świadomości” (ang. ASC), zarówno konkretnych metod, jak i interpretacji samych zjawisk. Stałymi elementami takich archaicznych praktyk i doktryn są: system ekwiwalencji mikro-makrokosmicznych, oparcie rytualizacji na matrycy cielesnej, wyrażające się w internalizacji struktur rytualnych z czasów wedyjskich ${ }^{22}$ (triadyczna struktura: ogień, soma i wiatr lub słońce, ogień i wiatr), oraz homogeniczność koncepcji ciała

${ }_{19}$ Bindu-kropla, punkt świadomości i samego życia. Na poziomie fizycznym identyfikowane z płynami prokreacyjnymi, na poziomie subtelnym - z czystym stanem świadomości.

${ }^{20}$ Termin „dosza” wydaje się częściowo ekwiwalentny do gr. humor z systemu medycyny Hipokratesa-Galena. Zob. R.P. Das, The Origins of the Human Being, Conception and the Female According to Ancient Indian Medical and Sexological Literature, Delhi 2000.

${ }_{21}$ Zob. na przykład Tantra in Practice, Introduction.

${ }^{22} \mathrm{Na}$ przykład odzwierciedlenie kształtów palenisk ofiary wedyjskiej w symbolach żywiołów powiązanych z poszczególnymi centrami ciała subtelnego (hierarchicznie ułożonych, zob. A. Wayman, Yoga of the Guhyasamäjatantra, Delhi, 1977, s. 66-67) czy internalizacja rytuału jako procesów 
wewnętrznego (subtelnego, doskonałego, diamentowego itp.) ${ }^{23}$. Oprócz metod jogicznych i tantrycznych religie bengalskie zazwyczaj wykorzystują niezwykle popularne metody nurtu pobożnościowego bhakti (bhakti) - ekstatyczny, wielogodzinny śpiew, żywiołowy, rytmiczny taniec przy akompaniamencie bębnów, długotrwałe powtarzania imion bóstwa ${ }^{24}$. Metody tak powszechnie wykorzystywane przez wyznawców nurtu bhakti zarówno wisznuickiego, śiwaickiego, jak i liczne bengalskie zakony sufich, są sprzężone z przywołanymi wcześniej metodami o charakterze jogicznym i tantrycznym.

Poniżej spróbuję ukazać na przykładzie wybranych elementów z religii bengalskich, jak struktury inicjacyjne i konkretne praktyki charakterystyczne dla tych religii potwierdzają tezę o trwałości rytuału kosztem doktryny i symboliki religijnej, a także sprawdzić, czy na terenie Bengalu istnieją dane potwierdzające trwałość tego rodzaju praktyk religijnych oraz skorelowanych z nimi archaicznych doktryn.

\section{Uniwersalne formy religijne w Bengalu}

Konserwatywność rytualna, specyficzne archaiczne sposoby myślenia wraz ze sztywnymi strukturami społecznymi wymagają (i generują) równie tradycyjne metody przekazu oraz cyrkulacji wiedzy dotyczącej inicjacji i rytuału. Jak pokazują przykłady z historii religii w Bengalu, przepływ pewnych koncepcji dotyczących praktyk religijnych był zawsze intensywny ${ }^{25}$. Ponadto w Bengalu (i szerzej w północnych Indiach) mamy do czynienia $\mathrm{z}$ uniwersalizacją zjawisk religii, to jest pojawiania się form religii o daleko posuniętym inkluzywizmie doktrynalnym, gdzie „najwyższa rzeczywistość” (cel soteriologiczny) jest przedstawiana jako wspólna dla wielu różnych nurtów religijnych. Odrębną kwestią przy rozpatrywaniu tego problemu jest użycie uniwersalnych metod, którymi są techniki jogiczne. Aplikacja metod jogicznych przez rozmaite grupy religijne w starożytnych i średniowiecznych Indiach jest dobrze znaną kwestią (na przykład joga w obrębie buddyzmu, hinduizmu, dżinizmu) ${ }^{26}$. W nurtach wisznuickiego bhakti joga jest traktowana instrumentalnie - to znaczy wykorzystuje się dyscyplinę jogiczną (o nacechowaniu tantrycznym) do osiągania własnych celów religijnych. Wydaje się ponadto, że adepci średniowiecznej jogi uważali się za (pomimo wyraźnej śiwaickiej proweniencji niektórych odłamów) praktykujących nurt o wysokim stopniu uniwersalizacji religijnego celu praktyk ${ }^{27}$. Joga jest traktowana jako dyscyplina, która może być zastosowana przez różnorakie grupy, bez względu na ich afiliację.

psychofizjologicznych i ich kontroli (na przykład Bryhadarnjaka Up., M. Eliade, Joga. Nieśmiertelność $i$ wolność, tłum. B. Baranowski, Warszawa 1997).

${ }^{23}$ Zob. R. Czyżykowski, op.cit.

${ }^{24}$ Idem, Droga do doskonałości w tradycji Ćajtanji. Wybrane aspekty praktyki religijnej $w$ wisznuzmie bengalskim, Kraków 2003, T.K. Stewart, op.cit.

${ }_{25}$ S.B. Dasgupta, Obscure Religious Cults as a Background for Bengali Literature, Calcutta 1995.

${ }^{26}$ Zob. na przykład Yoga in Practice, D.G. White (red.), Princeton 2011.

${ }_{27}$ Jak wskazuje J. Mallinson jedne z najwcześniejszych tekstów tradycji hatha-jogi mają kontekst wisznuicki. Zob. J. Mallinson, Dattātreya's Discourse on Yoga (edycja krytyczna w przygotowaniu). 
W klasycznej dla hatha-jogi kompilacji Swatmaramy (Svatmārāma) Hațhayōgapradīpika ${ }^{28}$ (XV wiek, zawiera wyjątki starszych dzieł) znajdujemy fragmenty wskazujące na takie właśnie pojmowanie celu praktyki jogicznej. I tak, kolejno: radźa-joga (rāja-yoga, ,joga królewska”, rozumiana tradycyjnie jako najwyższy stopień jogi, cel jogi, ekwiwalentny z samadhi (samādhi), a nie jako wyodrębniona ścieżka ${ }^{29}$ ), samadhi (również rozumiane jako cel jogi), amaratwa (amaratva, nieśmiertelność), laja-tattwa (layatattva, zasada rozpuszczenia), pustka-niepustka (śūnyāśūnya), param padam (parampadam, najwyższe osiągnięcie dla wisznuitów - świat Wisznu/Kryszny), adwaita (advaita, stan niedualny), dźiwanmukti (jīvanmukti, stan wyzwolenia za życia), sahadźa (stan wrodzony: przedkreacyjny, pierwotny), turija (turīya, „stan czwarty”, wyzwolenie) - wszystkie one są synonimiczne (eka vācakāh $)^{30}$. Zatem praktyka jogi jest potraktowana instrumentalnie, zaś jej cel ma charakter uniwersalny i pozornie odmienne cele różnych grup religijnych odnoszą się do jednej rzeczywistości ${ }^{31}$. Daje to możliwość włączania w obręb praktyk religijnych rytuałów i dyscyplin skutecznych w sensie generowania ASC oraz religijnie znaczących nastrojów podtrzymywania systemu symbolicznego, potwierdzania doktryny danej grupy. Bengalskie grupy religijne szeroko wykorzystywały tak ujętą jogę, ze szczególnym akcentem na metody tantryczne.

\section{Formy przekazu wiedzy ezoterycznej w Bengalu}

Przyjrzyjmy się teraz pokrótce formom przekazu wiedzy ezoterycznej w Bengalu. Transmisja wiedzy z zakresu rytualizacji religijnej może mieć rozmaity charakter. Przekaz wiedzy o charakterze ezoterycznym wyraża się w postaci rytuału inicjacji $(d \bar{i} k s \bar{a})$, która zwykle obejmuje przekazanie uczniowi mantry. Pewne elementy tej wiedzy mogą być prezentowane przed inicjacją, nie mają one jednak charakteru kluczowego. $\mathrm{Z}$ metodami rytualnymi zaznajamia się ucznia stopniowo. Zdarza się, że informacje o takim charakterze w zawoalowanej formie przekazywane są profanom w pieśni. Adept informuje w ten sposób o swoim doświadczeniu religijnym, trudnościach na ścieżce dyscypliny (sadhany, sādhana), a wydźwięk i okoliczności takiej komunikacji zdają się mieć w tym przypadku, przynajmniej częściowo, funkcję misyjną. W religiach indyjskich pieśń jako forma komunikowania społeczeństwu lub współwyznawcom o swoim doświadczeniu religijnym ma starożytne korzenie. Począwszy od pieśni mnichów i mniszek (palijskie Therī i Thera-gātha),

28 Svātmārama, Hațhayōgapradīpikā, wyd.: Hathayogapradipika. Light on Hatha Yoga, Commentary Swami Muktibodhananda Under the Guidance of Swami Satyananda Saraswati, New Delhi 2001.

${ }^{29}$ Ujęcie radźa-jogi jako odrębnej ścieżki, a nie szczebla w praktyce jogi pojawia się w dziewiętnastowiecznej interpretacji neowedantystów Wiwekananda. Zob. E. de Michelis, A History of Modern Yoga. Patanjali and Western Esotericism, London 2010.

${ }^{30}$ (IV.2-3): rājayogaḥ samādhiśca unman̄̄ ca manonman̄̄ amaratvam layastattvam śūnyāśūnyam param padam, amanaskam tathādvaitam nirālambam nirañjanam, jīvanmuktiśha sahajā turyā cetyekavāchakāh.

31 Podobna koncepcja pojawia się we wspomnianej Dattātreyayogaśastra. Zob. J. Mallinson, M. Singleton, Roots of Yoga, London 2016. 
przez pieśni tantrycznych „,doskonałych” (siddhów, siddha) lub „,wielkich doskonałych" (mahasiddhów, mahasiddha) ${ }^{32}$, aż po współczesnych wędrownych mistyków Bengalu, baulów, pieśni odgrywały istotną rolę w przekazie informacji o doświadczeniu religijnym. Rytualizacja o charakterze jawnym - rytuały publiczne, kolektywne mogą również być limitowane, a uczestnictwo w nich ograniczane do inicjowanych członków. Nie oznacza to, że szczegóły rytualne są dostępne dla ogółu, wiedza o nich jest zwykle przypisana specjalistom rytualnym i aktywnym uczestnikom rytuału ${ }^{33}$. Zatem podstawową formą transmisji ezoterycznej wiedzy jest przekaz wiedzy bądź mocy (śakti), charyzmy religijnej na linii nauczyciel (guru) - uczeń (śisya). Szerszym terminem oznaczającym zwykle tradycję jest sampradaja (sampradāya). Przekaz wiedzy religijnej często następował w obrębie rodziny, w ten sposób powstawały w kręgach wisznuizmu bengalskiego „dynastie” inicjujących i nauczających guru (vaṃśā - ród, dynastia). System hierarchiczny dźati również przyczynił się do powstania odrębnych grup wisznuickich tożsamych $\mathrm{z}$ daną kastą, tak zwanych dźati-wisznuitów (jāti vaiṣnava) ${ }^{34}$. Linie guru wisznuitów tantrycznych funkcjonują podobnie do innych systemów indyjskich i nie są systemem dziedzicznym. Przekaz metod praktyki religijnej ma przede wszystkim charakter oralny, teksty pełniły istotną, choć ograniczoną rolę. Źródła, którymi dysponujemy, dają niestety ograniczony obraz ezoterycznych aspektów religii bengalskich. Brak komentarzy i niezwykle hermetyczny język sprawiają, że interpretacja naukowa tej literatury sprawia ogromne problemy ${ }^{35}$.

\section{Tantryczne praktyki w średniowiecznych religiach Bengalu i ciało subtelne}

W wypadku religii bengalskich wykorzystujących metody tantryczne, począwszy od buddyzmu, przez różne formy hinduizmu, aż po sufizm, odnotowujemy całe spektrum różnych praktyk religijnych i doktryn opartych na wymienionych niżej elementach. Ich rdzeń pozostaje względnie stały i zaskakująco trwały w zestawieniu ze zmiennością form samych religii. Jest nim kompleks praktyk opierających się na tym, co określamy jako sadhana lub bhadźana (sādhana, bhājana) - dyscyplina, praktyka religijna o charakterze tantrycznym, hatha-joga wzbogacona o elementy tantryczne (joga rozumiana jako uniwersalny, ponadkonfesyjny kompleks inicjacyjny), zachowanie bindu (bindu-dhāraṇi), wykorzystanie mantr, kontrolowanego

${ }^{32}$ Dohā-Gīti-Kośa of Saraha Pāda (A Treasury of Song in Dohā Mātre) and Caryā-Gīti Kośa (A Treasury of the Cārya Songs of Various Siddhas), H.C. Bhayani, Restored Text, Sanskrit Chāyā and Translation, Ahmedabad 1997, P. Kværne, An Anthology of Buddhist Tantric Songs, A Study of the Caryagiti, Bangkok 2010.

${ }^{33}$ Zob. charakterystykę grupy ezoterycznej: E. Tiryakian, Sociology of Esoteric Culture, s. 265. Cyt. za: G. Djurdjevic, Masters of Magical Powers, The Nath Siddhas in the Light of Esoteric Notions, nieopublikowana praca doktorska, The University of British Columbia, 2005, s. 49.

34 R. Chakravarty, Vaișnavism in Bengal, 1486-1900, Calcutta 1986.

35 Zob. R. Czyżykowski, Selected Aspects of the Textual Studies on the Vaiṣnava Sahajiya Tradition in Medieval Bengal, „Cracov Indological Studies” 2016, vol. XXVIII, s. 339-366. 
aktu seksualnego (maithunya, beng. yugala), różne formy bhakti - pobożności i rytualizacji. Wymienione elementy mogą się pojawiać w różnych kombinacjach w zależności od charakteru grupy. Poniżej zajmuję się modelami ciała wewnętrznego - ten aspekt religii bengalskich, łączący sferę doktrynalną z praktyczną, uwidoczni i pozwoli na odniesienie wcześniej przyjętych założeń do konkretnego materiału źródłowego.

Model zakładający obecność w ciele centrów, „Zworników” subtelnych kanałów, kręgów, obrazowanych także jako zbiorniki substancji wydaje się uniwersalny i jest świetnym przykładem prezentowanej tu koncepcji trwałości struktur rytualnych i związanych z nią archaicznych form myślenia (pierwsze tego rodzaju koncepcje znajdujemy w najstarszych upaniszadach: Bryhadaranjaka i Ćhandogja ${ }^{36}$ ). Sama koncepcja takiego ciała i jego wariacje wydają się niezwykle skomplikowanym zagadnieniem, a jego powstanie jest skorelowane $\mathrm{z}$ danym ekosystemem, tradycjami medycznymi (klasyczną medycyną indyjską oraz regionalnymi ludowymi tradycjami), językiem, wreszcie - stanowi wynik określonych praktyk wypróbowanych przez konkretne tradycje w ciągu wieków ${ }^{37}$. Niżej ograniczymy się do zaprezentowania paru koncepcji związanych właśnie z obszarem Bengalu.

Najwcześniejsze odnotowane we wschodnich Indiach modele ciała subtelnego to schematy obecne w tekstach wadźrajany zawarte w Hewadźra-tantrze (Hevajratantra) i we wspomnianych już pieśniach Ćarja-giti (Ćarja-pada). Hewadźra-tantra ilustruje wczesny model pojmowania ciała subtelnego w tradycji annuttarajogi-tantr (anuttarayogatantra). Mówi się tam o ciele diamentowym (vajra-deha), w którym znajdujemy cztery ćakry, czyli ,kręgi” (cakra):

1. Kreacji (nirmāna cakra) - lotos o sześćdziesięciu czterech płatkach - genitalia

2. Dharmy (dharma cakra) - lotos o ośmiu płatkach - serce

3. Połączenia (sambhoga cakra) - lotos o szesnastu płatkach - gardło

4. Wielkiej Błogości (mahāsukha cakra) - trzydzieści dwa płatki - głowa ${ }^{38}$.

Paręset lat późniejszy model ciała wewnętrznego czy doskonałego, który znajdujemy w bengalskim wisznuizmie tantrycznym, wydaje się przedłużeniem wczesnego modelu buddyjskiego. Możemy go datować na wieki XVI-XVII, przynajmniej jeśli chodzi o dostępne nam teksty (niewykluczone, że samo jego powstanie jest wcześniejsze). Tutaj również pojawiają się cztery centra w ciele wewnętrznym, a dokładniej cztery zbiorniki, stawy (sarovara) (wpływ wisznuickiego mitu lub tradycji alchemicznej?):

1. Staw pożądania (kāma-sarovara) - genitalia

2. Staw dumy (māno-sarovara) - brzuch/serce

36 Zob. szczegółowe omówienie: R. Czyżykowski, Ciało..., s. 74-77.

37 Zob. D. Wujastyk, Interpreting the Image of the Human Body, „International Journal of Hindu Studies" 2009, vol. 31, 2, s. 189-228.

38 Hewadźra-tantra, I. 1.24 (edycje: The Concealed Essence of the Hevajra Tantra with the Commentary Yogaratnamālā, tłum. G.W. Farrow, I. Menon, New Delhi 2001, [The] Hevajratantra A critical study, transl. D.L. Snellgrove, Bangkok 2000). Zdaniem D.G. White'a tekst ten i Ćaryagiti są tekstami, w których po raz pierwszy pojawia się idea lokalizacji czterech ćakr w rejonie genitaliów, serca, gardła i głowy (D.G. White, Kiss of the Yogini, s. 224). 
3. Staw miłości (prema-sarowara) - serce

4. Staw nieśmiertelności (akșaya-sarovara) - głowa ${ }^{39}$.

Równolegle w sufizmie bengalskim w siedemnastowiecznym dziele Yoga-qalandriya (arab. qalandriya) odnajdujemy schemat czterech stacji (maqām) w ciele jogina ${ }^{40}$ :

1. Jabrüt-głowa (czoło)

2. Malqūt-pępek

3. Lāhüt-serce

4. Nāsūt-dolny region.

Zatem struktura centrów w ciele wewnętrznym we wszystkich przypadkach jest spójna, natomiast semantyka rytualna i symbolika zmieniają się w zależności od tradycji. Wadźra-deha opiera się na poczwórnym schemacie buddyzmu mahajany, a model wisznuicki - na teologii wisznuickiej, koncepcji rasy i transformacji emocji. Z kolei model suficki podstawia pod poszczególne maqam między innymi postaci archaniołów. W ostatnim wypadku, co charakterystyczne, zarówno cztery centra, jak i umieszczenie symbolu węża w pępku (kundalini, ognista Ćandali z Hewadźra-tantry) bardziej korelują się z modelem wadźrajany niż z jakimkolwiek schematem hinduistycznym. Bez względu na te różnice widać wyraźnie, jak w ciągu bez mała tysiąca lat utrzymuje się pojmowanie ciała wewnętrznego jako składającego się z czterech głównych ośrodków ${ }^{41}$. Można określić ten model jako archaiczny, ponieważ widoczne są tu echa buddyjskiego schematu ciała subtelnego mniej więcej z VIII wieku, a być może nawet z wcześniejszego okresu. W średniowiecznych nurtach śiwaicko-śaktyjskich inne schematy cielesne niewątpliwie funkcjonowały w Bengalu równolegle, jak na przykład popularny model sześciu ćakr, przedstawiony w Szatćakranirupana (șațcakranirūpaṇa), powstały prawdopodobnie w Assamie, a więc na obszarze oddziaływania kultur bengalskich (tzw. Wielki Bengal) ${ }^{43}$. Jednak aż do mniej więcej XVIII-XIX wieku takiego schematu ciała jogicznego nie można uznać za dominujący. Niewątpliwie niektóre grupy konstruujące swoje własne modele ciała wewnętrznego były świadome istnienia schematu sześciu ćakr, na co wskazują próby korelacji na przykład sufickich centrów maqam z poszczególnymi ćakrami czy wisznuicki Nigudartha-prakaśawali (Nigụ̣̈̂̂artha prakāśāvalī, czyli Objaśnienie tajemnych znaczeń) Gauri Dasy (Gauri Dāsa $)^{44}$.

${ }^{39}$ Taki schemat pojawia się w XVII w. w Amrtaratnavali Mukunadewy, zob.: Caitanya prathama cārițī sahajiyā punthi, Paritoṣ Dāsa (red.), wprow. Gopīnātha Kavirāja, Calcutta 1972 oraz thumaczenie fragmentów na język angielski: G.A. Hayes, The Necklace..., op.cit.

${ }^{40}$ K.E. Cantu, op.cit., s. 37, E.M. Haq, op.cit., s. 379-384.

${ }^{41}$ XVIII i XIX w. przynoszą zanik właśnie takich specyficznych modeli bengalskich ciała subtelnego (cztery centra) na rzecz modelu sześciu ćakr znanego z tradycji śiwaicko-śaktyjskich (oraz innych schematów).

${ }^{42}$ Sir J. Woodroffe, The Serpent Power Being the Saț-cakranirūpana and Pādukā-pañcaka, Two Works on Laya Yoga, translated from the Sanskrit, with introduction and commentary, Ganesh and Company, Madras [reprint 2009].

${ }^{43}$ Schemat sześciu ćakr pojawia się także w innych tekstach tradycji śiwaicko-śaktyjskiej. Zob. D.G. White, Kiss..., s. 221-222.

${ }^{44}$ Gauri Dāsa, Nigūẹhārtha-prakāśāval̄̄, Mss 5252, Bangiya Sahitya Parishad, Kolkata (edycja manuskryptu i tłumaczenie fragmentów w przygotowaniu w ramach projektu wspomnianego w przyp. 1). 


\section{Podsumowanie}

Podsumowując, należy stwierdzić, że na obszarze Bengalu odnotowujemy specyficzny model czterech centrów w ciele subtelnym, bez względu na to, czy mamy do czynienia z buddyzmem, wisznuizmem czy też sufizmem. Archaiczne struktury myślenia i praktyk pozostają względnie stałe, natomiast symbolika i strona znaczeniowa przyporządkowywana poszczególnym elementom są inwariantne. Praktyki o charakterze tantrycznym - wizualizacje, praktyki mantryczne, jogiczna kontrola psychofizjologiczna również odznaczają się wysoką homogenicznością i trwałością, mimo ich adaptacji na potrzeby owego systemu symbolicznego, w przypadku nowych grup religijnych pojawiających się na obszarze Bengalu. Zgodnie z przyjętymi na początku założeniami teoretycznymi można uznać, że „składnia rytualna” związana $\mathrm{z}$ osiąganiem różnie określanego celu religijnego pozostaje względnie stała, zmienia się jedynie semantyka rytuału. Od czasów dominacji buddyzmu w Bengalu możemy prześledzić trwałość określonych struktur rytualnych oraz użycie stałej terminologii (sahaja, vartamāna, samarasa, vastu), a przywołane wyżej schematy ciała subtelnego możemy potraktować jako specyficzne „mapy” przestrzeni wewnętrznej, odwzorowania doświadczeń mistycznych, ale też „przewodniki” rytualne dla kolejnych pokoleń adeptów, czyli teksty warunkujące kształt doświadczenia mistycznego, które również pozostawały względnie stałe i powtarzalne.

Nakreślony wyżej schemat cyrkulacji wiedzy o praktykach rytualnych niewątpliwie był gwarantem skuteczności transmisji treści sakralnych, intrygujący jest jednak przekaz tego rodzaju wiedzy w przypadku zmiany dominującej grupy religijnej i przeniesienia samych praktyk do nowej grupy. Problem, jaki tu się pojawia, to pytanie, $w$ jakim zakresie przebiega transmisja praktyk inicjacyjnych opartych na konkretnych rytuałach oraz jak owe rytuały mają się do aspektów znaczeniowych i symbolicznych religii danego nurtu. Praktyki o charakterze tantrycznym, w których dokonuje się kontrolowanego aktu seksualnego, rytualnej identyfikacji uczestników z boskimi bytami, manipulacja płynami cielesnymi - wszystkie te elementy wchodzą do stałego repertuaru praktyk bengalskich nurtów tantrycznych, zarówno hinduistycznych, buddyjskich, jak i sufickich. Za konkretnymi praktykami stoi określona doktryna, ale też „wiara” (śraddha) w to, że tego rodzaju praktyki są skuteczne i mają boskie pochodzenie. Równolegle podąża specyficzna dla danej grupy interpretacja symboliczna. Praktyki kontynuuje się, ponieważ są efektywne w sensie generowania zmienionych stanów świadomości, inaczej trudno wytłumaczyć ich trwałość.

\section{Bibliografia}

Bose M.M., The Post-Caitanya Sahajiyā Cult of Bengal, Calcutta 1930.

Caitanya prathama cārițī sahajiyā punthi, Paritoṣ Dāsa (red.), wprow. Gopīnātha Kavirāja, Calcutta 1972.

Cantu K.E., Theurgy and the Snake: The Yoga Kalandar and Bengali Sufism, Saarbrucken 2015.

Chattopadhyaya A., The People and Culture of Bengal, a Study in Origins, vol. I, Kolkata 2002. 
Chakravarty R., Vaiṣnavism in Bengal, 1486-1900, Calcutta 1986.

Czyżykowski R., Ciało mistyczne i fizyczne w tradycji wisznuizmu sahadźija, Kraków 2013.

Czyżykowski R., Droga do doskonałości w tradycji Ćajtanji. Wybrane aspekty praktyki religijnej w wisznuizmie bengalskim, Kraków 2003.

Czyżykowski R., Selected Aspects of the Textual Studies on the Vaiṣnava Sahajiya Tradition in Medieval Bengal, „Cracov Indological Studies” 2016, nr 18, s. 339-366.

Das P., Sahajyā Cult of Bengal and Pancha Sakha Cult of Orissa, Calcutta 1988.

Das P., Sahajiyā o gaudīya vaiṣnava dharma, Calcutta 1978.

Das R.P., Problematic Aspects of the Sexual Rituals of the Bauls of Bengal, „Journal of the American Oriental Society" 1992, vol. 112, nr 3 (Jul. - Sep.), s. 388-432.

Das R.P., The Origins of the Human Being, Conception and the Female According to Ancient Indian Medical and Sexological Literature, Motilal Banarsidass, Delhi 2000.

Dasgupta S.B., Obscure Religious Cults as a Background for Bengali Literature, Calcutta 1995.

Davidson R.M., Indian Esoteric Buddhism, Social History of the Tantric Movement, Delhi 2002.

Dohā-Gīti-Kośa of Saraha Pāda (A Treasury of Song in Dohā Mātre) and Caryā-Gīti Kośa (A Treasury of the Cārya Songs of Various Siddhas), H.C. Bhayani, Restored Text, Sanskrit Chāyā and Translation, Ahmedabad 1997.

de Michelis E., A History of Modern Yoga. Patanjali and Western Esotericism, London 2010.

Dimock E.C., The Place of the Hidden Moon: Erotic Mysticism in the Vaisnava Sahajīya Cult of Bengal, London-Chicago 1989.

Eliade M., Joga. Nieśmiertelność i wolność, tłum. B. Baranowski, Warszawa 1997.

Gauri Dāsa, Nigūạhārtha-prakāśāvalī, Mss 5252, Bangiya Sahitya Parishad, Kalkuta (edycja manuskryptu i thumaczenie fragmentów w przygotowaniu w ramach projektu wspomnianego w przyp. 1).

Grabowska B., Powstanie, rozkwit i zmierzch liryki wisznuickiej XII-XX wieku, Warszawa 1995.

Hatha-yoga-pradipika, Swatmarama, wyd.: Hathayogapradipika. Light on Hatha Yoga, Commentary Swami Muktibodhananda Under the Guidance of Swami Satyananda Saraswati, New Delhi 2001.

Hatley S., Mapping the Esoteric Body in the Islamic Yoga of Bengal, „History of Religions” 2007, vol. 46, nr 4, s. 351-368.

Hayes G.A., Metaphoric Worlds and Body Symbolism in Vaiṣnava Sahajiyā Tantric Traditions [w:] Yoga: Essays on the Indian Tradition, I. Whicher (red.), London 2003.

Hayes G.A., The Necklace of Immortality: A Seventeenth-Century Vaiṣnava Sahajiyā Text [w:] Tantra in Practice, D.G. White (red.), Delhi 2001.

Hayes G.A., Tradycje wisznuizmu sahadźija w średniowiecznym Bengalu [w:] Praktyki religijne w Indiach, S. Lopez (red.), Warszawa 2002.

Haq M.E., A History of Sufism in Bengal, Asiatic Society of Bangladesh, Dacca 1975,

„Journal of the Royal Asiatic Society”, London: JRAS, Pub., 1909, s. 1053-1054.

Kværne P., An Anthology of Buddhist Tantric Songs, A Study of the Caryagiti, Bangkok 2010.

Krysznadasa Kawiradźa Goswamin, Caitanya Caritāmrta, tłum. i wprow. E.C. Dimock Jr., wprow. i wyd. T.K. Stewart, Cambridge, London 1999.

Mallinson J., Dattātreya's Discourse on Yoga (edycja krytyczna w przygotowaniu).

Mallinson J., Singleton M., Roots of Yoga, London 2016.

McDaniel J., The Madness of the Saints:Ecstatic Religion in Bengal, Chicago 1989.

Meshel N.S., The 'Grammar' of Sacrifice: A Generativist Study of the Israelite Sacrificial System in the Priestly Writings with a 'Grammar' of $\Sigma$, Oxford 2014.

Penner H., Language, Ritual and Meaning, „Numen. International Journal of the History of Religions" 1985, vol. 32, s. 1-16.

Samuel G., The Originis The Origins of Yoga and Tantra; Indic Religions to the Thirteenth Century, Cambridge 2008. 
Stewart T.K., Godna naśladowania pobożność stugi Hariego [w:] Praktyki religijne w Indiach, D. Lopez (red.), Warszawa 2001.

Șat-cakra-nirūpana: Woodroffe John Sir, The Serpent Power Being the Șat-cakranirūpana and Pādukā-pañcaka, Two Works on Laya Yoga, transl. from the Sanskrit, with introd. and comment., Ganesh and Company, Madras [reprint 2009].

Tiryakian E., Sociology of Esoteric Culture, s. 265. Cyt. za: G. Djurdjevic, Masters of Magical Powers, The Nath Siddhas in the Light of Esoteric Notions, nieopublikowana praca doktorska, The University of British Columbia, 2005.

Urban H.G., Ecstatic Songs of Bengal, Tantric and Devotional Songs from Colonial Bengal, Oxford 2001.

Staal F., The Meaningless of the Ritual, „Numen” 1979, vol. XXVI, fasc. I.

Staal F., The Rules Without Meaning. Ritual, Mantras and the Human Sciences, New York-BernFrankfurt am Main-Paris 1989, wyd. indyjskie: Ritual and Mantras. Rules without Meaning, New Delhi 1996.

Tantra in Practice, D.G. White (red.), Princeton 2001.

Wayman A., Yoga of the Guhyasamājatantra, Delhi, 1977, s. 66-67.

Woodroffe J., Sir, The Serpent Power Being the Șat-cakranirūpana and Pādukā-pañcaka, Two

Works on Laya Yoga, Translated from the Sanskrit, with Introduction and Commentary, Ganesh and Company, Madras [reprint 2009].

Wujastyk D., Interpreting the Image of the Human Body, „International Journal of Hindu Studies” 2009, vol. 31, 2, s. 189-228.

Yoga in Practice, D.G. White (red.), Princeton 2011. 